\title{
Makli Sindhi Islamic Architecture consolidation Techniques (Anastolysis)
}

\author{
Javaria Manzoor Shaikh \\ Erasmus Mundus European Masters of Building repair and Diagnosis (Spain, Italy and Poland),PhD student Healthcare Architecture \\ department Hanyang University,Low Energy House M.Arch UET, Lahore,Indus Valley School B.Arch, Karachi \\ *Corresponding Author: javeria@hanyang.ac.kr
}

Copyright (C) 2014 Horizon Research Publishing All rights reserved.

\begin{abstract}
The semi monolithic site of Makli is of critical importance in terms of understanding the socio-economic processes present at this time in the Sindh, Pakistan. Scholars have drawn conclusions about the semi monolithic technologies employed at later historic sites at Makli, based on attributes identified within experimental datasets. This research aims to show that the interpretation of the relationship between the experimental and archaeological datasets and questions the monolithic production strategy is shown to be constrained by the quality of the raw material. This interpretation and the association of these sites with a distinctive personal have important implications for our understanding of regional settlement systems and the placement of the graves at this sacred site. Here there is a discussion on how to use the process of anastolysis, since there is a need to conduct the alastolysis process for the site, for the reassembling of the un assembled parts.
\end{abstract}

Keywords Anastylosis Makli Sindhi Islamic Architecture Consolidation Techniques

\section{Introduction}

Makli Hill Tombs, Unesco World Heritage Site, Thatta, Sind (Sindh), Pakistan. This is one of the largest necropolises in the world, with a diameter of approximately 8 kilometres, Makli Hill is the burial place of some 125,000 Sufi saints. It is located on the outskirts of Thatta, the capital of lower Sindh until the seventeenth century, in what is the south-eastern province of present-day Pakistan. The tomb of the Samma King, Jam Nizam al-Din (reigned 1461-1509), is an impressive square structure built of sandstone and decorated with floral and geometric medallions. The semi Monolithic, dry assemblages of the joints from the sites between the Jamia Masjid and Jam Nizamudin tomb, is Jam Tamachi canopy this case study, situated on an irregular typography; is inclined towards west, hence here a systematic chronological aspect attributes, in the context because the canopy is situated on an inclining slop, this permits the dry assemblages joints to dislocate, due to the slight change in the slop form.

Anastylosis (from the Ancient Greek: $\alpha v \alpha \sigma \tau \eta \dot{\lambda} \lambda \omega \sigma \mathrm{s},-\varepsilon \omega \varsigma$; $\alpha v \alpha$, ana = "again", and $\sigma \tau \eta \lambda$ ó $\omega=$ "to erect (a stela or building)") is an archaeological term for a reconstruction technique whereby a ruined building or monument is restored using the original architectural elements to the greatest degree possible. It is also sometimes used to refer to a similar technique for restoring broken pottery and other small objects. 1

The cultural landscape of the Makli site is notable for its extreme variability. Researchers have defined and studied this variability mainly through semi monolithic typology and, specifically, the frequencies of certain construction tool types. The work described in this research represents an attempt to determine the place of new assemblage's procedure yet keeping intact the integrity of the old architecture, at the northern site of Makli, within the region's chronological and cultural framework. This research has led to questions about the way we study our Sindhi cultural variability in the region generally. Surveys and test carried out here have discovered at least two sites at Makli in different exposures of what seems to be the same period. Although one of these fits easily by conventional criteria into the Geometric patterns, the other is more problematic and complex due to Hindu influence. Its assemblage presents an apparent contradiction between some evidence that suggests a semi monolithic assignment due to porosity of the stone and other more porous material: brick, including more dense stone that support a later date due to less wear and tear as observed at the Jamia Masjid, mosque area.

\footnotetext{
${ }^{1}$ From Wikipedia, the free encyclopedia
} 


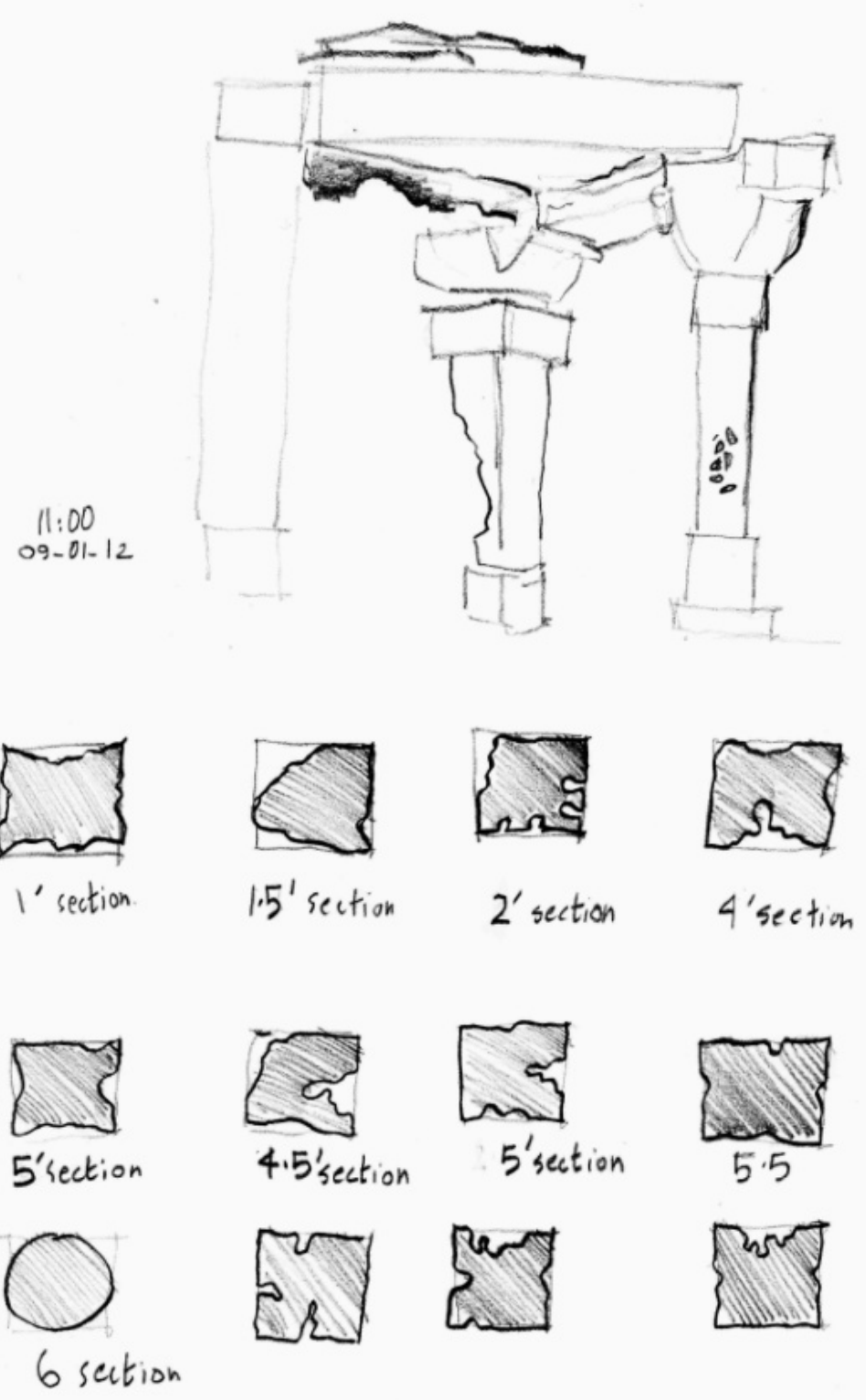

\section{Hydrous characteristic of the Stone}

Capillarity - the movement of a liquid in the interstices of porous material due to surface tension at the border of solid and liquid; the parameter of capillarity is a height of water movement $\mathbf{h}$

$$
\mathrm{h}=\frac{2 \sigma \cos \theta}{\operatorname{rg} \rho_{\mathrm{p}}}
$$

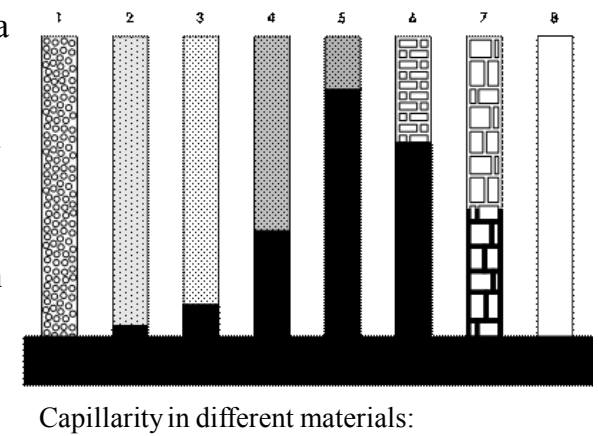

$\sigma$ - surface tension; $\theta$ - interfacial angle; $\mathrm{g}$ - free fall acceleration; $\mathrm{r}-$ capillar radius; $\rho$ - density of a liquid.

1 - gravel, crushed ; 2 - coarse sand; 3 - fine sand; 4 - slush; 5 - clay; 6 - brick wall; 7 masonry of dense stone; 8 - semi monolithic dense stone.

Figure 1. the capillary action is represented here, the water travels upwards. The figure represent the porosity density of the stone material, some are highly packed an other are relatively less dense, this result in the different pattern in deterioration of the stone material at the Makli tomb complex. 
In general phenomenon, it is observed that the remains of the sites located in Sindh suffered a lot mostly due to age, human neglect variations of atmospheric condition, severe temperature and natural disasters.

Though the main causes of decay are summarised as under:

1). Salt Action

2). Moisture in filtration from ground and atmosphere

3). Direct rains

4). Structural distress including extreme thermal stress, poor site drainage, material decay and visitors behaviour.

The research presents the above mentioned aspects and their effects on a semi destroyed structure next to Jamia Masjid, a series of the cut sectional plans of the semi monolithic column, hence the deterioration pattern is studied, the air actually hit the structure, and react with the stone and as a result the pours widens in this process. Over a period of 500 years the pours has grown up to several inches and then, the pours increases so much is this fashion that it carves a natural deep cavity, and then this cavity increases in diameter, in a shape of a spoon form. When two diagonal cavities meet each other as results is lost of a piece from the column stone. In this way the shape of the column is completely loss as shown in the sections. As the process continues the structure could also collapse.

Hence the stone material is "tired" to performance and its durability decreases under different influences for varying reasons, The causes of decay are material properties or structure properties or by environmental influences. Hence repair2 is required.

Unless a new policy of protection and integrated conservation is urgently implemented, our society will shortly find itself obliged to give up the heritage of buildings and sites which form its traditional environment. (Page three Congress on the European architectural heritage $21-25$ October 1975 The Declaration of Amsterdam)

\section{The Ways, the Water and the Salt Enters the Stone Walls of Makli}

Infiltration due to damage in the structure or geometry of the walls. Ascension by capillarity from underground. Condensation of air humidity on cold walls Rain water pushed on the walls by wind Horizontal filtration and condensation

\section{Makli Hill Tombs, Unesco World Heritage Site, Thatta, Sind (Sindh), Pakistan}

This is one of the largest necropolises in the world, with a

2 Repair is a replacing or correction of technical and performance properties of a material (element, structure, and building) to certain serviceability and durability. diameter of approximately 8 kilometers, Makli Hill is supposed to be the burial place of some 125,000 Sufi saints. It is located on the outskirts of Thatta, the capital of lower Sindh until the seventeenth century, in what is the south-eastern province of present-day Pakistan. The tomb of the Samma King, Jam Nizam al-Din (reigned 1461-1509), is an impressive square structure built of sandstone and decorated with floral and geometric medallions.

What is repair of structure and why it is needed?

Repair is a replacing or correction of technical and performance properties of a material (element, structure, and building) to certain serviceability and durability.

Because material is "tired" to performance and its durability decreases under different influences for reasons:

Caused by material properties predominantly or by structure properties predominantly or by environmental influences predominantly

The most important aspect of conservation is an action to prolong the decay, "Without Architecture, we cannot remember..." John Ruskin, Seven Lamps of Architecture, Here comparative analysis of both the laws is discussed:

The primitive definition of the antiquity or monument is (b) "ancient" means belonging or relating to any period prior to 2 [the preceding hundred years]; The antiquities act, 1968, which was then amended in 1075 and the period was reduced to seventy five years.

The major point of conservation from the different Charts of conservation of Europe is analysed. Since the new buildings of today will be the heritage of tomorrow, every effort must be made to ensure that contemporary architecture is of a high quality. (Page one congress on the European architectural heritage 21 - 25 October 1975 The Declaration of Amsterdam)Unless a new policy of protection and integrated conservation is urgently implemented, our society will shortly find itself obliged to give up the heritage of buildings and sites which form its traditional environment. (Page three Congress on the European architectural heritage 21 - 25 October 1975 The Declaration of Amsterdam)

Frequently accompanied by salt migration crystallization break down into sulphates / chlorides / nitrates (coming from the ground)

Since water moves by capillarity it depends on three aspects

- Capillarity size of the material

- Thickness of the wall

- Evaporation at the wall surface over the area of capillarity rise.

The Makli site is a live graveyard that means it's a still being used as a burial chamber, though it is an illegal act according to the UNESCO law, which strictly prohibit unplanned new additions. This can be analysed in the charter: Integrated conservation is achieved by the application of sensitive restoration techniques and the correct choice of appropriate functions. It should be noted that integrated conservation does not rule out the introduction of 
modern architecture into areas containing old buildings provided that the existing context, proportions, forms, sizes and scale are fully respected and traditional materials are used. (Page 3 European Charter of the Architectural Heritage Adopted by the Council of Europe, October 1975).

The East wall which is inclining, of the Jamia Masjid Makli, where the Mehrab is also located, is been encroached as a burial place of Mali Mai, which is not planned. This could be studied in the Figure 2 .

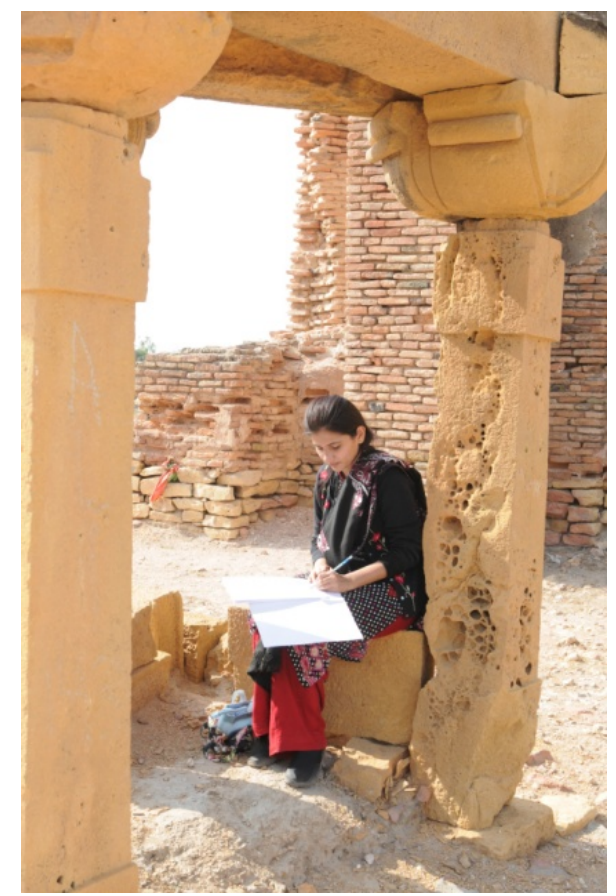

Figure2. the picture and the sketch showing the burial chapmber of Mai Makli.

The technique Figure 2: This monument is totally distorted due to misplacement and displacement, coupled with the porosity and deterioration of the stone

\subsection{Sandstone Decay}

There are three primary factors related to the decay of sandstone: mineralogical composition and the physical make-up of the stone fabric; environment, or exposure to damaging agents such as water, salt and corrosive chemicals; and use, how the stone is quarried, shaped, and installed in a structure.

\subsection{Classification of deterioration reasons of building structures and materials}

Stone replacement can be the most viable approach for restoring large areas of damage. A new anchoring system may be required. Resetting returns displaced stone to its original position.

Here the recovered portions of the displaced canopy is been analysed, the missing parts could be remoulded and could be used at Makli. In the case of ruins, scrupulous conservation is necessary, and steps should be taken to reinstate any original fragments that may be recovered (anastylosis), whenever this is possible; the new materials used for this purpose should in all cases be recognisable. (The Athens Charter for the Restoration of Historic Monuments Adopted at the First International Congress of Architects and Technicians of Historic Monuments, Athens 1931)

The figure 2 represent the porosity density of the stone material, some are highly packed another are relatively less dense, this result in the different pattern in deterioration of the stone material at the Makli tomb complex.

The pattern of deterioration is formulated according to the pattern of density, the lesser dense stone in the structure deteriorate faster whereas the stone which is more dense deteriorate is retarded speed. This results in a symmetrical format of deterioration in the stone as shown bellow.
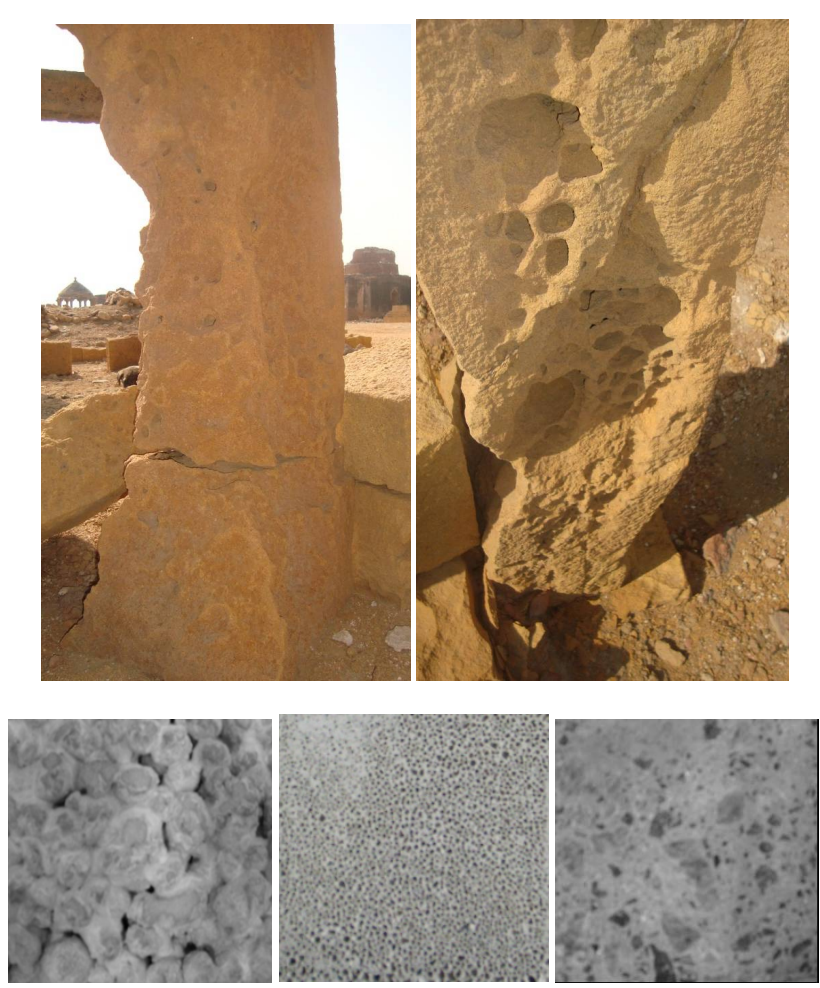

Figure 3. capillary analysis Sectional plan of the column (monolithic) micropores $(<1 \mathrm{~mm})$ and macropores $(1 \ldots 3 \mathrm{~mm})$; low-porosity less than $30 \%$, medium-porosity closed from 30 to $50 \%$ high-porosity more than $50 \%$ and open; Pores are divided into:Yellow sand stone of Makli, are divided into three.

\subsubsection{Materials for restoration: Selection reasons}

1) Structural Pores are divided into two categories closed and open; this is micropores $(<1 \mathrm{~mm})$ and macropores $(1 \ldots 3$ $\mathrm{mm}$ ); These Architectural materials used at Makli are divided into: low-porosity, less than $30 \%$, medium-porosity from 30 to $50 \%$, high-porosity more than $50 \%$. whereas capillarity is also been observed - the movement of a liquid in the interstices of porous material due to surface tension at the border of solid and liquid; the parameter of capillarity is a height of water. 


\subsection{Composition}

Sandstone is a clastic sedimentary rock. Also known as layered rocks, sedimentary rocks are formed by one of two processes. Clastic sedimentary rocks form through the accumulation of rock particles by water or wind action. Organic/chemical sedimentary rocks form by accumulation of organic material or by chemical precipitates from ocean water.4 In most clastic sedimentary rocks, including sandstone, the grains are quartz. Quartz is a hard, chemical-resistance silicate mineral not directly attacked by most weathering agents; however, the size and shape of the grains are responsible for the pore size and texture of the rock. Pore space is a major factor in the durability of the stone.

The grains of the sandstone are held together by one of four types of cementing matrix:

1) siliceous, in which silica or silicon dioxide is the binder;

2) calcareous, in which calcite is the binder;

3) ferruginous, in which iron oxides, usually limonite, are the binder; and

4) argillaceous, in which clays are the binder. Some sandstones have more than one type of binder.

5) The importance of the matrix in determining the durability of the stone was recognized as early as the 1880's

6) The matrix can be attacked by water or by wateror air-bornecorrosive agents.

\subsection{Integrated conservation averts these dangers.}

Integrated conservation is a technique which is suggested here in Makli, since this is a live heritage, and it still continues to be used, therefore the area could be allocated for the new tombs, and this need to be done appropriately. Hence integrated conservation this is done by the application of sensitive restoration techniques and the correct choice of appropriate functions as compared to the existing context, proportions, forms, sizes and scale are fully respected and traditional materials are used. (Page 3 European Charter of the Architectural Heritage Adopted by the Council of Europe, October 1975)

The structure of sandstone is the final aspect of composition related to decay. Sandstone is a sedimentary rock formed in layers as the grains are deposited. Structure is the type and thickness of the layers or beds. The thickness of the beds can range from less than one inch to many feet. The seams between the beds are a natural line of weakness in the stone Sandstone's aggregate, matrix, and structure, along with its geographical source and color, combine to classify the sandstone. For example, the stone used in this research is from the Connecticut River Valley. It is a red/brown ferruginous sandstone with primarily quartz aggregate. It has medium-size grains and beds of 2 to 18 feet thick, although tremendous variations in fabric exist

\subsection{Environment}

The second major influence on the decay of sandstone is the environment. The stone is exposed to damaging agents like water, salt, wind, atmospheric pollution, and microorganisms. Human contact can damage a building through misuse, or acts of vandalism. The environment of any structure is a complicated system, and it is rare that any single decay mechanism occurs alone. Water is the most crucial factor in sandstone decay because it is itself damaging, and it is the delivery agent for many other decay mechanisms.

The arrangement of the grains in the stone results in open spaces or pores. These pores allow liquid water and water vapor to travel through the stone. Water can come from the atmosphere in the form of rain or vapor or it can come from the ground. Water alone can damage sandstone through the processes of hydric dilatation, the volumetric expansion of a material in the presence of liquid water, and hygric dilatation, expansion in a humid environment. Argillacious or clay-bound sandstones are particularly vulnerable because clays swell a great deal. Hydric and hygric dilatation can damage the stone by breaking the bonds between grains and thereby dislodging the grains.

Although the stone will contract to its original dimension when it dries, wet/dry cycling and its resultant expansion and contraction can cause material fatigue and more serious damage. The combination of water and freezing temperature results in a similar decay mechanism. Water expands when it freezes displacing grains and eventually dislodging them. The joints between the beds are a natural weak point in the stone and are particularly vulnerable to these types of decay.

\section{The Technique of Conservation}

The anastolysis process is needed where, there are broken parts available at the site, In the case of ruins, scrupulous conservation is necessary, and steps should be taken to reinstate any original fragments that may be recovered (anastylosis), whenever this is possible; the new materials used for this purpose should in all cases be recognisable. (The Athens Charter for the Restoration of Historic Monuments Adopted at the First International Congress of Architects and Technicians of Historic Monuments, Athens 1931)

The classification of deterioration reasons of building structures and materials for the hexagonal canopy design, the stone used for the anastolysis could be reused or Stone replacement can be the most viable approach for restoring large areas of damage. A new anchoring system may be required. To assemble the sections of the columns, present at the site. Resetting is also required to returns displaced stone to its original position.

Therefore re-anchoring is a process necessary where the movement of the stone from its original position has broken existing anchors or fractured the back of the stone. This is been noticed at the lower part of the column where the material is deteriorated more then $50 \%$. 
Crack repair is technique which can be applied for the columns lower part before reinstalling, this can be accomplished by injecting an adhesive material into the fissure to provide water impermeability and prevent further cracking. A minor crack can be successfully repaired by routing the crack and filling it with patching material. On the other hand, Consolidation is a time-tested technique of reconstituting softened or deteriorated stone by filling the voids and binding the grains within the stone. Consolidation has many applications for the preservation of such stone present at Makli historic structures, but requires thorough testing and evaluation to ensure that the consolidate leaves a compatible vapor-permeable surface.

The basic aspects for the material to restored and conserved at the Makli monuments are, firstly Compatibility (mechanical, physical, chemical) with ancient materials; i.e. the new column for the purpose of anastolysis is sculpted which according the older structure which is found on the site. Secondly Reversibility; i.e. ability to being removed; this mean that if tomorrow some better conservationist come up with a better plan to conserve the site of Makli, should be able to recognise easily the newly added material and could reverse the entire process and reinstall the material according to the better program.

And thirdly Absence of harmful aftereffect (consequence of application) on the monument this means that the material installed should be long lasting. The repair techniques includes that the cracked spalled or exfoliated stone must be repaired in a timely manner to prevent further damage. Typical repair methods includes Patching is used to repair small of damaged stone with a matching cementation material that is applied and built up in layers until it matches the original profile. For larger patches, pins might be needed to secure the new material, on to the stone column, as shown in figure 3 as under.

Sedimentary rocks: Texturing: Stone durability

The higher the porosity and the surface roughness the deeper the corrosion process, would take place. Hence, in the process the most active factors are cycling wetting -drying, freezing - thawing causing unstable components destruction, micro cracking, glance loss and finally deterioration can be observed. Hence here corrosion can be decreased.

Igneous rocks $\rightarrow$ Metamorphic rocks $\rightarrow$ Sedimentary rocks

Carbonate rocks $(\mathrm{CaCO} 3)$ destroy under influence of acid rains, alkalines:

$$
\begin{gathered}
\mathrm{CaCO}_{3}+\mathrm{CO}_{2}+\mathrm{H}_{2} \mathrm{O} \rightarrow \mathrm{Ca}\left(\mathrm{HCO}_{3}\right)_{2} \\
\mathrm{CaCO}_{3}+2 \mathrm{H}_{2} \mathrm{O}+2 \mathrm{SO}_{2} \rightarrow 2\left(\mathrm{CaSO}_{4} 2 \mathrm{H}_{2} \mathrm{O}\right)+2 \mathrm{CO}_{2} \\
\mathrm{CaCO}_{3}+\mathrm{HCl} \rightarrow \mathrm{CaCl}_{2}+\mathrm{H}_{2} \mathrm{CO}_{3} \\
\mathrm{CaCO}_{3}+2 \mathrm{NaOH} \rightarrow \mathrm{NaCO}_{3}+\mathrm{Ca}(\mathrm{OH})_{2}
\end{gathered}
$$

Environmental properties: Igneous rocks used here at Makli, are disposed to accumulation of raised radionuclide amount in different types of masonry stone and types of stone masonry used at Makli, these are effected by following environmental pollutions.
Chemical fumes (ozone, sulfur dioxide, oxides of nitrogen) in combination with sand, dust, wind (coatings, masonry, metals, polymers)

Biostability (bactericidal resistance) - the ability of a material to withstand biological influence of inferior plant and low organisms

Radiation resistance - the ability of a material to withstand different types of sun radiation without changing their properties and destruction. It is the strongest performance factor.

Hence stone masonry deteriorating at Makli, sectional plan of the column (monolithic) as shown in figure eight, where veneer stone, Anchors and anchorage for stone work can be seen. Damp proofing stone is used in Makli hill site, though here the damp proofing treatment is provided at base courses will act as a barrier to moisture migration into stone. These are used sealant joints in lieu of mortar joints reduces water entrance

For the protection of stone masonry from deterioration, on the one hand Structural methods is necessary, this includes water drain and appropriate jogs, and on the other hand preservation this includes mineral solutions or polymer percolation for pores mudding.

Therefore for the preparation of building stone for repair and restoration the three primary steps are; primarily correct selection of rock type and suitable for restoration, secondly definition of stonework type and finally reproduction of stone texture and dressing.

The important requirements for the repair fill are the quality to withstand sufficient water-repellency, secondly high vapor permeability for moisture drainage regulation, and thirdly High volume of internal porosity for salts sedimentation. Hence the material suitable for the fill are categorised as under. Sculpting is the process required here for the columns to be re-carving since they are badly eroded stone or re-accentuating indistinct detailing. Though this method is frequently employed to repairing ornamentation.

Cracks filling

Before cracking filling determination of cracking reason and its stabilization

Single short crack filled cement mortar

Cracks up to $4 \mathrm{~cm}$ width filled by cement and polymer mortars injections

- Injection materials for cracks

- Types of injection materials:

- acrylic;

- epoxy resins;

- paraffine;

- polyurethane resins;

- silane (organic-silicon);

- sylicates;

- siloxanes.

For such a site which is Monolithic in nature, architectural practice: Stone 'dry' masonry. Limestone Protective Coatings Waterproof coatings should rarely, if ever, be used on stone. Although these coating prevent water infiltration, they have a tendency to trap moisture 
within the stone and the masonry in general. Even water-repellent sealers will prevent the natural migration of water from stone and should be used with great caution, if at all.

The anastylosis process is evident at the Makli site, where the pieces are joint together to form an irregular structure, but this is not planned and is not done by the designers, but rather untrained workers hence the structure is not amended in an appropriate manner, and is just assembled randomly, using different columns sizes. A triangular plan structure is formed above.

\section{Conclusions}

Re-assemblage and intent of anastylosis is to rebuild, from the original materials, historical architectural monuments which have fallen into ruin. This is done by placing components back into their original positions. Where standing buildings are at risk of collapse, the method may entail the preparation of drawings and measurements, piece-by-piece disassembly, and careful reassembly, with new materials as required for structural integrity; occasionally this may include new foundations. When elements or parts are missing, modern materials (of restoration grade) may be substituted, such as plaster, cement, and synthetic resins.

The international Venice Charter of 1964 details criteria for anastylosis. For instance or such as the antiquity act of Pakistan. First, the original condition of the structure must be confirmed scientifically. Second, the proper placement of each recovered component must be determined. And third, supplemental components must be limited to those necessary for stability (that is, substitute components may never lie at the top), and must be recognizable as replacement materials. New construction for the sake of filling in apparent lacunae is not allowed.

Anastylosis has its detractors in the scientific community. In effect, the method poses several problems among which few of them are as:

No matter how rigorous preparatory studies are, any errors of interpretation will result in errors, often undetectable or incorrigible, in reconstruction.

Damage to the original components is practically inevitable.

An element may be, or may have been reused in, or may have originated in, different buildings or monuments from different periods. To use it in one reconstruction obviates its use in others.

\subsection{The Process of Anastolysis Followed at Makli, is as follows}

1. Cleaning the material located on the site of Makli, with soft brushes to remove ingrained dirt. Do not use dust cloth, if dirt is extensive, use a paste jelly formula such as EDTA ammonium carbonate.

2. Washing the stone with distilled water by brushing, spraying or by immersion or paper pulp method on stones showing symptoms of salting.

3. Sterilize by brushing or spraying with a minimum $25 \%$ to $36 \%$ hydrogen peroxide stones affected by presence of organic growths such as mosses and lichens.

4. Consolidate by brushing, spraying or injecting (or by impregnating, filling, grouting, jointing or pin dowel adhesive) on very dry stone using a consolidant such as Rinforzante $\mathrm{H}$ or ethyl silicate for siliceous stone (granite, sandstone). Consolidation is recommended when the cohesive strength of stone has weakened and there is a need to consolidate or bind together the disintegrated material.

5. Gap filling, replacement and/or retouching of missing parts.

6. In appropriate circumstances, water repellents may be applied. Spray or brush protective films or water repellents on stone affected by chemical integration and biological attack. Common protectants are waxes, acrylic and silicon resins.

The significance of the process is that anastolysis is the only methodology available to reassemble the dislocated parts which are available on the site

\section{REFERENCES}

[1] Legislation for protection and management of archaeology heritage of Pakistan complied by Rafique Mughal.

[2] http://www.sentistoria.org/Articoli/malanga/C18) 20GUERRE $\% \quad 20 \mathrm{LE} \% \% \% \quad 20$ the $\%$ 20STELLARI 20MOHENJO-DARO.pdf

[3] World Heritage sites in Pakistan 2000 UNESCO

[4] Endowment Fund Trust (Hameed Akhund, Mohan Lal)

[5] Ministry of Culture (secretary Aziz Uqaili, Minster Sassi Palejo

[6] Antiquity cell

[7] Heritage Foundation Pakistan (Yasmeen Laro)

[8] UNESCO World Heritage Centre

[9] International Council on Monuments and Sites

[10] The International Scientific Committee on the Analysis and Restoration of Structures of Architectural Heritage

[11] Related reference

[12] Context, The official journal of the IHBC

[13] "Art conservation and restoration." Encyclopædia Britannica. 2010. Encyclopædia Britannica Online. 29 Apr. 2010 $<$ http://www.britannica.com/EBchecked/topic/36477/art-con servation-and-restoration $>$

[14] "Art conservation and restoration." Encyclopædia Britannica. 2010. Encyclopædia Britannica Online. 29 Apr. 2010 $<$ http://www.britannica.com/EBchecked/topic/36477/art-con servation-and-restoration> 
[15] http://www.usatoday.com/weather/news/2007-06-08-colosse um_N.htm

[16] http://www.abc.net.au/news/stories/2008/04/13/2215521.htm

[17] http://encyclopedia.stateuniversity.com/pages/16759/Parthen on.html

[18] "Art conservation and restoration," Encyclopædia Britannica. Encyclopædia Britannica Online. Encyclopædia Britannica, 2010. Web. 26 Apr. 2010

[19] The Institute of Historic Building Conservation The UK's Professional body for historic environment conservation professionals

[20] UNESCO Asia-Pacific Heritage Awards for Culture Heritage Conservation.

[21] Architectural Conservation Programme at The University of Hong Kong, Asia's leading postgraduate-level professional programme in built-heritage conservation.

[22] Cultural Heritage Management Programme in the School of Professional and Continuing Education at The University of Hong Kong, a postgraduate-level professional programme

[23] Antiquities and Monuments Office, responsible for the conservation of local cultural heritage.
[24] James W. Dossett, "Composite Repair of Sandstone" (Master's Thesis, University of Pennsylvania, 1998), 1.

[25] Erhard M. Winkler, Stone in Architecture: Properties, Durability, 3d ed. (Berlin, Heidelburg, New York: Springer-Verlag, 1994), 19.

[26] Eugene C. Robertson, "Physical Properties of Building Stone," in Conservation of Historic Stone Buildings (Washington: Committee on Conservation of Historic Stone Buildings and Monuments,

[27] National Materials Advisory Board, Commission on Engineering and Technical Systems, National Research Council, 1982), 82. Julien, 74.

[28] R. Snethlage and E. Wendler, "Moisture Cycles and Sandstone Degradation," in Report of the

[29] Dahlem Workshop on Saving Our Architectural Heritage: The Conservation of Historic Stone

[30] Structures Held in Berlin 3-8 March 1996, eds. N.S. Baer and R. Snethlage (Chichester, New

[31] York, Weinheim, Brisbane, Singapore, and Toronto: John Wiley \& Sons, 1997), 9. 